\title{
Comparison of Techniques for Obtaining Centric Relation Based on the Reproducibility of the Condylar Positions in Centric Relation-A Systematic Review
}

\author{
Clóvis Lamartine de Moraes Melo Neto ${ }^{10}$ Daniela Micheline dos Santos ${ }^{1,2}$ \\ André Pinheiro de Magalhães Bertoz ${ }^{3}$ André Luiz de Melo Moreno ${ }^{1}$ Marcelo Coelho Goiato ${ }^{1,2}$ \\ ${ }^{1}$ Department of Dental Materials and Prosthodontics, School of \\ Dentistry, São Paulo State University, Araçatuba, São Paulo, Brazil \\ Address for correspondence Marcelo Coelho Goiato, DDS, MS, PhD, \\ Department of Dental Materials and Prosthodontics, School of \\ 2 Oral Oncology Center, School of Dentistry, São Paulo State \\ University, Araçatuba, São Paulo, Brazil \\ Dentistry, São Paulo State University, Street: José Bonifácio - 1193; \\ Araçatuba, São Paulo 16015-050, Brazil (e-mail: m.goiato@unesp.br).
}

${ }^{3}$ Department of Pediatric and Social Dentistry, School of Dentistry,

São Paulo State University, Araçatuba, São Paulo, Brazil

Eur J Dent 2022;16:251-257.

Abstract

Keywords
- dental centric relation
- reproducibility of
findings
- jaw relation record
- chin point guidance
- bimanual
- manipulation
- gothic arch
- swallowing

The objective of this systematic review was to compare centric relation (CR) techniques that belong to the same method of obtaining CR (guided, graphical, or physiological method), to verify which CR technique within each method of obtaining CR generates the greatest reproducibility of the condylar positions (or mandibular position) in CR. The PubMed, Cochrane Library, SciELO, Scopus, and Web of Science databases were searched for articles published up to May 5, 2021. The search terms were combinations of "dental centric relation" (MeSH), with each of the following terms (individually): "reproducibility of findings" (MeSH); "jaw relation record" (MeSH); "chin point"; "gothic arch"; "bimanual manipulation"; "swallowing" (MeSH); and "jig." Inclusion criteria: clinical studies in English; individuals without temporomandibular dysfunction and with complete or almost complete dentition or complete edentulous; and comparison between $\mathrm{CR}$ techniques belonging to the same method of obtaining CR based on the reproducibility of condylar positions in CR. For each method of obtaining the $C R$, the following $C R$ techniques were considered: guided method (chin point guidance and bimanual manipulation); graphic method (intraoral and extraoral gothic arch tracing); and physiologic method (swallowing and tongue retrusion along the palate). A total of 1692 articles were screened. After the inclusion and exclusion criteria were applied, six articles were included in this review. None of the included studies evaluated edentulous individuals. All included articles compared CR techniques of the guided method. Three articles concluded that the bimanual technique showed greater reproducibility of the condylar positions in CR than the chin point guidance technique, two articles showed equivalence between these techniques, and 1 article concluded that the chin point guidance technique showed greater reproducibility of the condylar published online

December 17, 2021
DOI https://doi.org/

10.1055/s-0041-1735903. ISSN 1305-7456. (c) 2021. The Author(s).

This is an open access article published by Thieme under the terms of the Creative Commons Attribution License, permitting unrestricted use, distribution, and reproduction so long as the original work is properly cited. (https://creativecommons.org/licenses/by/4.0/)

Thieme Medical and Scientific Publishers Pvt. Ltd., A-12, 2nd Floor, Sector 2, Noida-201301 UP, India 
positions in CR than the bimanual technique. Thus, in this systematic review, the bimanual technique was often superior (generated greater reproducibility of the $C R$ ) or at least equivalent to the chin point guidance technique. Therefore, for individuals with complete dentition and without temporomandibular disorders, the bimanual technique is more recommended.

\section{Introduction}

The definition of centric relation (CR) has been redefined several times over the years. ${ }^{1-3}$ The most recent edition of the Glossary of Prosthodontic Terms states that CR is "a maxillomandibular relationship, independent of tooth contact, in which the condyles articulate in the anterior-superior position against the posterior slopes of the articular eminences; in this position, the mandible is restricted to a purely rotary movement; from this unstrained, physiologic, maxillomandibular relationship, the patient can make vertical, lateral or protrusive movements; it is a clinically useful, repeatable reference position." 1,2

CR is inherently individual to each person. ${ }^{2}$ Thus, regardless of the definition of $\mathrm{CR},{ }^{1,3}$ the dentist must gently guide the patient's mandible in the direction posterior to the maximum intercuspation, until the patient's anatomical components (e.g., muscles, ligaments, condyles, and discs) and physiological limits establish his or her CR. It is worth mentioning that CR must not be forcibly established. ${ }^{2}$

CR is important for both dentate and edentulous individuals, because it plays an important role in prosthetic rehabilitation, temporomandibular disorder (TMD) therapy, orthodontic and maxillofacial planning, occlusal rehabilitation, and maintenance of oral health. ${ }^{2}$ The ultimate goal of the $\mathrm{CR}$ record is to achieve harmonious relationships between teeth, joints, and muscles. ${ }^{2}$ Therefore, a CR technique that generates the greatest reproducibility of condylar positions in CR plays an extremely important role in clinical practice. $^{2}$

The most commonly used CR classical techniques are bilateral manipulation and chin point guidance, which are considered guided methods (i.e., they belong to the guided method of obtaining $\mathrm{CR})^{2,4}$; intraoral and extraoral gothic arch tracing, which are considered graphic methods (i.e., they belong to the graphic method of obtaining $(\mathrm{CR})^{2,4}$; and the swallowing technique and tongue retrusion along the palate, which are considered physiologic methods (i.e., they belong to the physiologic method of obtaining CR). ${ }^{2,4}$

In a recent systematic review, de Moraes Melo Neto et al compared classical CR techniques of different methods of obtaining $\mathrm{CR}$ to verify which $\mathrm{CR}$ technique generated the greatest reproducibility of the condylar positions in $C \mathrm{R}^{2}$ Thus, the present study aims to assess another situation; that is, the objective of this systematic review is to compare $\mathrm{CR}$ techniques that belong to the same method of obtaining CR (guided, graphical, or physiological method), to verify which $C R$ technique within each method of obtaining CR generates the greatest reproducibility of the condylar positions (or mandibular position) in CR.

\section{Methods}

This study followed the Preferred Reporting Items for Systematic Reviews and Meta-Analyses (PRISMA) criteria proposed for a systematic review. ${ }^{5}$ This systematic review was registered on PROSPERO (international prospective register of systematic reviews, CRD42018097285) at the beginning of the study. Then, the population (P), intervention (I), comparison (C), and outcome $(\mathrm{O})$ were determined to form a research question:

$>\mathbf{P}$-individuals submitted to techniques for obtaining $\mathrm{CR}$.

$>$ I-techniques for obtaining CR.

>C-Comparison between CR techniques belonging to the same method of obtaining $C R$, based on the reproducibility of the condylar positions (or mandibular position) in CR.

$>\mathbf{0}$-The expected result is to know which CR technique, within each method of obtaining the $\mathrm{CR}$, can generate the greatest reproducibility of the CR.

\section{Search Strategy and Selection of Studies}

Two calibrated independent reviewers ${ }^{2}$ (C.L.d.M.M.N. and M.C. G.) conducted a search in the PubMed, Cochrane Library, SciELO, Scopus, and Web of Science databases for relevant articles published up to May 5, 2021. The search terms were combinations of "dental centric relation" (MeSH) with each of the following terms (individually): "reproducibility of findings" (MeSH); "jaw relation record" (MeSH); "chin point"; "gothic arch"; "bimanual manipulation"; "swallowing" (MeSH); and "jig." After duplicate articles were excluded, the titles and abstracts of all potentially eligible studies were screened, according to the inclusion and exclusion criteria, and studies that clearly did not meet the criteria were eliminated. ${ }^{2}$ The full text of each remaining preselected article was then evaluated, according to the inclusion and exclusion criteria, and those articles that met these criteria were included in this systematic review. ${ }^{2}$

\section{Inclusion Criteria}

Clinical studies in English evaluating individuals without TMD. ${ }^{2}$

$\square$ Individuals with complete or nearly complete dentition (angle class I, II, or III) or complete edentulism. ${ }^{2}$

Studies must evaluate at least five individuals. ${ }^{2}$

Studies must compare at least two CR techniques belonging to the same method of obtaining $\mathrm{CR}$, based on the reproducibility of $\mathrm{CR}$. 
For each method of obtaining $C R$, the following $C R$ techniques were considered:

* Graphic method-Intraoral and extraoral gothic arch tracing were considered. ${ }^{2}$

* Physiologic method-The swallowing technique and tongue retrusion along the palate were considered. ${ }^{2,4}$

* Guided method-Bimanual manipulation and chin point guidance were considered. ${ }^{2,4}$ As in the study by de Moraes Melo Neto et $\mathrm{al}^{2}{ }^{2}$ the chin point guidance technique could be its traditional version ${ }^{4}$ and its modified version (three finger chin point guidance technique). ${ }^{4}$

\section{Exclusion Criteria}

Duplicated studies. $^{2}$

Removable partial denture wearers. ${ }^{2}$

Studies that did not inform the individual's dental condition. $^{2}$

$\square$ Clinical studies with incomplete data. ${ }^{2}$

Literature reviews. $^{2}$

Systematic reviews. ${ }^{2}$

Case reports. $^{2}$

\section{Kappa Method}

The agreement between the two reviewers based on the evaluation of titles and abstracts, and later on the evaluation of the full text of the articles, was evaluated using the Kappa statistic.

\section{Quality Assessment}

The quality of the studies was assessed with the Jadad scale. ${ }^{2,6}$ This scale evaluates if the study is randomized and double-blind, if these factors are well described, and if there is a description of dropouts in each study. ${ }^{2,6}$ For each question, the answer can be "yes" ( 1 point) or "no" ( 0 points) ${ }^{2,6}$ After the sum of the scores, the study is considered of low quality if the result is from 0 to 2 , or high quality if the result is from 3 to 5 . $^{2,6}$

\section{Data Analysis}

The following data were collected from the studies: sex and age of participants; ${ }^{2}$ sample size; ${ }^{2}$ dental condition of the participants (dentate or edentulous); ${ }^{2}$ techniques used for obtaining $\mathrm{CR}{ }^{2}$ whether randomization of techniques was performed; ${ }^{2}$ period of the day for obtaining $\mathrm{CR} ;^{2}$ the position of the individual during $\mathrm{CR}$ registration; ${ }^{2}$ the number of repetitions of $\mathrm{CR}$ techniques; ${ }^{2}$ the instrument or apparatus used to compare CR techniques; ${ }^{2}$ and the number of operators. ${ }^{2}$

\section{Results}

From an initial total of 1692 identified studies, 12 articles $^{7-18}$ were selected for full-text analysis (Kappa score $=1.00$ ), resulting in the inclusion of six clinical studies ${ }^{7-12}$ (Kappa score $=1.00$ ) that met the inclusion and exclusion criteria (-Fig. 1). The quality analysis of the studies according to the Jadad scale showed that all articles were of low quality
(-Table 1). The reasons for exclusion of the other articles that received a full-text review are indicated in -Table 2. $^{13-18}$ - Tables $\mathbf{3}$ and $\mathbf{4}$ show the data collected from the six articles included in this systematic review. ${ }^{7-12}$

None of the six included studies evaluated edentulous individuals. Therefore, the six articles included evaluated individuals with complete dentition (-Table 3). ${ }^{7-12}$ All comparisons were only between the bimanual and chin point guidance techniques. ${ }^{7-12}$ Kantor et al, Hobo and Iwata, and Keshvad and Winstanley found that the bimanual technique generated greater reproducibility of the condylar positions in $\mathrm{CR}$ when compared with the chin point guidance technique. ${ }^{7,10,11}$ Simon and Nicholls and Galeković et al found that there was no difference between these techniques, based on the reproducibility of condylar positions in CR. ${ }^{8,12}$ Only Teo and Wise found that the chin point guidance technique generated greater reproducibility of the condylar positions in CR compared with the bimanual technique. ${ }^{9}$

\section{Discussion}

All studies included in this systematic review were considered of poor quality, according to the Jadad scale. ${ }^{6}$ Despite this, studies comparing CR techniques cannot be doubleblind, since the operator must know which $\mathrm{CR}$ technique will be performed on the patient. ${ }^{6}$

Only Simon and Nicholls and Teo and Wise performed the CR techniques randomly. ${ }^{8,9}$ Randomization is considered the gold standard for determining the effectiveness of medical/dental interventions in clinical research, and it should have been used in all studies included in this systematic review. $^{2}$

Kantor et al, Hobo and Iwata, and Keshvad and Winstanley observed that the bimanual technique generated greater reproducibility of the condylar positions in CR than the chin point guidance technique., 10,11 Therefore, half of the articles included in this systematic review showed a superiority of the bimanual technique. . $^{10,11}$ Theoretically, this result can have occurred because, when performing the bimanual technique, the dentist can stabilize and guide the patient's mandible more efficiently with her or his hands compared with the chin point guidance technique, in which the patient's mandible is stabilized with just one of the dentist's hands. Thus, possibly the bimanual technique generates a lower chance of error during the manipulation of the individual's mandible.

Two articles showed no difference between the CR techniques based on the reproducibility of the condylar positions in $C R ;{ }^{8,12}$ and only one article showed that the chin point guidance technique generated greater reproducibility of the condylar positions in CR than the bimanual technique. ${ }^{9}$ Therefore, when evaluating the results of the six articles, ${ }^{7-12}$ it is possible to suggest that the bimanual technique is more advantageous for the dentist.

A very important fact to be highlighted is that the $C R$ techniques of the guided method are more dependent on the dentist than the CR techniques of the graphical and physiological methods. ${ }^{2}$ Thus, the greater the dentist's experience 


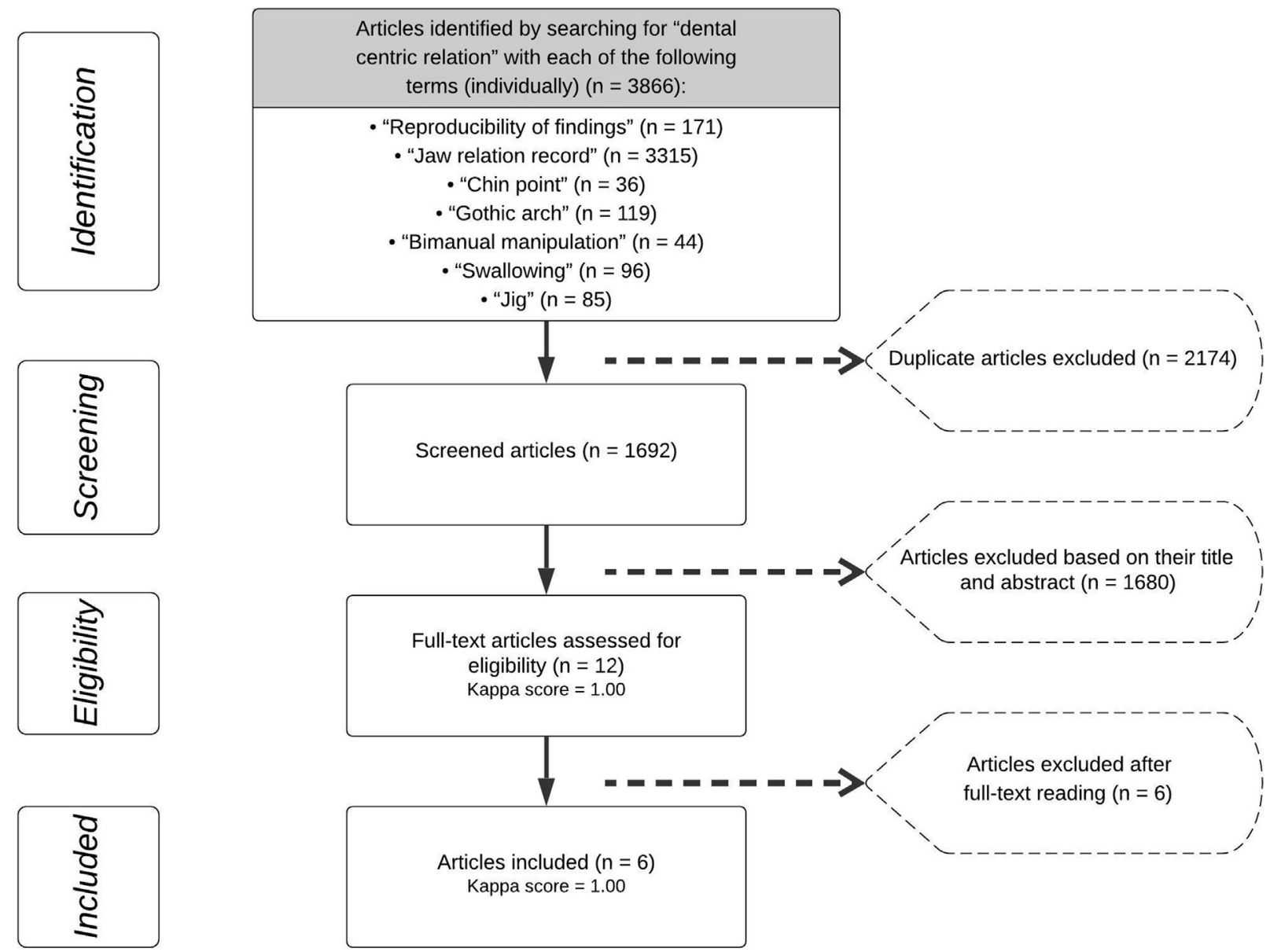

Fig. 1 PRISMA flowchart showing the process of identification, screening, eligibility and inclusion of articles.

Table 1 Scores reached by the articles following the criteria of the Jadad scale

\begin{tabular}{|l|l|l|l|l|l|l|}
\hline Jadad scale & $\begin{array}{l}\text { Kantor } \\
\text { et al }\end{array}$ & $\begin{array}{l}\text { Simon and } \\
\text { Nicholls }\end{array}$ & $\begin{array}{l}\text { Teo and } \\
\text { Wise }^{9}\end{array}$ & $\begin{array}{l}\text { Hobo and } \\
\text { Iwata }^{10}\end{array}$ & $\begin{array}{l}\text { Keshvad and } \\
\text { Winstanley }^{11}\end{array}$ & $\begin{array}{l}\text { Galeković } \\
\text { et al }^{12}\end{array}$ \\
\hline 1. Was the study described as randomized? & 0 & 1 & 1 & 0 & 0 & 0 \\
\hline 2. Was the randomization described and appropriate? & 0 & 1 & 1 & 0 & 0 & 0 \\
\hline 3. Was the study described as double-blind? & NA & NA & NA & NA & NA & NA \\
\hline 4. Was the double-blind method appropriate? & NA & NA & NA & NA & NA & NA \\
\hline 5. Was there a description of withdrawals and dropouts? & 0 & 0 & 0 & 0 & 0 & 0 \\
\hline Results & 0 & 2 & 2 & 0 & 0 & 0 \\
\hline Quality of study & Low & Low & Low & Low & Low & Low \\
\hline
\end{tabular}

Abbreviation: NA, not applicable.

Table 2 Reason for exclusion after reading the articles in full

\begin{tabular}{|l|l|}
\hline Reason & References \\
\hline Repeated article & Kantor et al ${ }^{13}$ \\
\hline $\begin{array}{l}\text { Studies that did not compare } \\
\begin{array}{l}\text { CR techniques based on the } \\
\text { reproducibility of condylar } \\
\text { positions in CR }\end{array}\end{array}$ & $\begin{array}{l}\text { Carwell and Mcfall, }{ }^{14} \\
\text { McWilliam, }^{15} \text { Hellsing }_{17} \\
\text { et al }\end{array}$ and Watanabe $^{16}$ \\
\hline $\begin{array}{l}\text { Lack of information about the } \\
\text { technique }\end{array}$ & McKee $^{18}$ \\
\hline
\end{tabular}

Abbreviation: $C R$, centric relation. with a RC technique belonging to the guided method, the greater the chance that this type of RC technique is performed correctly.

Only Teo and Wise (supine) and Keshvad and Winstanley (upright) reported the position of patients during CR records. ${ }^{9,11}$ Furthermore, only Keshvad and Winstanley and Hobo and Iwata reported that one operator performed all CR techniques in their studies. ${ }^{10,11}$ The position of the patient (supine or upright) during $\mathrm{CR}$ recording is an important factor, since it may influence his or her mandibular position (i.e., the patient's mandible may be more posterior 
Table 3 Part 1 of data collection of selected article

\begin{tabular}{|c|c|c|c|c|c|c|c|c|}
\hline Author/year & $\begin{array}{l}\text { Total of } \\
\text { individuals }\end{array}$ & $\begin{array}{l}\text { Women } \\
(n)\end{array}$ & $\begin{array}{l}\text { Men } \\
(n)\end{array}$ & Age & $\begin{array}{l}\text { Dental } \\
\text { condition }\end{array}$ & Guided method & $\begin{array}{l}\text { Graphic } \\
\text { method }\end{array}$ & $\begin{array}{l}\text { Physiological } \\
\text { method }\end{array}$ \\
\hline Kantor et $\mathrm{al}^{7}$ & 15 & 3 & 12 & $21-45$ & $\begin{array}{l}\text { Complete } \\
\text { dentition }^{a}\end{array}$ & $\begin{array}{l}\text { Chin point guidance } \\
\text { with and without } \\
\text { JIG/Bimanual }\end{array}$ & $\mathrm{NE}$ & $\mathrm{NE}$ \\
\hline $\begin{array}{l}\text { Simon and } \\
\text { Nicholls }\end{array}$ & 5 & 5 & 0 & $\begin{array}{l}\text { Third } \\
\text { decade } \\
\text { of life }\end{array}$ & $\begin{array}{l}\text { Complete } \\
\text { dentition }^{a}\end{array}$ & $\begin{array}{l}\text { Chin point guidance } \\
\text { (JIG)/Bimanual (JIG) }\end{array}$ & $\mathrm{NE}$ & $\mathrm{NE}$ \\
\hline Teo and Wise ${ }^{9}$ & 7 & NR & NR & $17-29$ & $\begin{array}{l}\text { Complete } \\
\text { dentition }^{a}\end{array}$ & $\begin{array}{l}\text { Chin point guidance } \\
\text { (JIG)/Bimanual (JIG) }\end{array}$ & $\mathrm{NE}$ & $\mathrm{NE}$ \\
\hline Hobo and Iwata ${ }^{10}$ & 10 & NR & NR & $21-32$ & $\begin{array}{l}\text { Complete } \\
\text { dentition }^{a}\end{array}$ & $\begin{array}{l}\text { Chin point guidance } \\
\text { (JIG)/Bimanual (JIG) }\end{array}$ & $\mathrm{NE}$ & $\mathrm{NE}$ \\
\hline $\begin{array}{l}\text { Keshvad and } \\
\text { Winstanley }^{11}\end{array}$ & 14 & 7 & 7 & $26.61 \pm 4.2$ & $\begin{array}{l}\text { Complete } \\
\text { dentition }^{\mathrm{a}}\end{array}$ & $\begin{array}{l}\text { Chin point guidance } \\
\text { (JIG)/Bimanual (JIG) }\end{array}$ & $\mathrm{NE}$ & NE \\
\hline Galeković et al ${ }^{12}$ & 32 & 16 & 16 & $20-33$ & $\begin{array}{l}\text { Complete } \\
\text { dentition }\end{array}$ & $\begin{array}{l}\text { Chin point guidance } \\
\text { (JIG)/Bimanual (JIG) }\end{array}$ & $\mathrm{NE}$ & $\mathrm{NE}$ \\
\hline
\end{tabular}

Abbreviations: CR, cenric relation; NE, not evaluated; NR, not reported.

JIG-This means that the jig was used to deprogram proprioceptive memory.

Galeković et al reported that the jig used by them was a cotton pellet. The other studies used Lucia's jig.

Chin point guidance with ramus support (Simon and Nicholls) and chin point guidance associated with applied muscle force by the subject (Teo and Wise) were not considered in this systematic review.

${ }^{a}$ Angle classification not provided.

${ }^{\mathrm{b}}$ Angle class I.

Table 4 Part 2 of data collection of selected articles

\begin{tabular}{|c|c|c|c|c|c|c|}
\hline Authors & $\begin{array}{l}\text { Randomization } \\
\text { of techniques }\end{array}$ & Evaluation period & $\begin{array}{l}\text { Patient } \\
\text { position }\end{array}$ & $\begin{array}{l}\text { Number of records } \\
\text { per technique }\end{array}$ & $\begin{array}{l}\text { Evaluation } \\
\text { apparatus }\end{array}$ & $\begin{array}{l}\text { Number of } \\
\text { operators }\end{array}$ \\
\hline Kantor et $\mathrm{al}^{7}$ & NR & NR & NR & 6 & $\begin{array}{l}\text { Articulator and } \\
\text { mechanical } \\
\text { microscope }\end{array}$ & NR \\
\hline $\begin{array}{l}\text { Simon and } \\
\text { Nicholls }\end{array}$ & Yes & NR & NR & 5 & $\begin{array}{l}\text { Custom aluminum } \\
\text { plate with three } \\
\text { measuring points }\end{array}$ & NR \\
\hline $\begin{array}{l}\text { Teo and } \\
\text { Wise }^{9}\end{array}$ & Yes & NR & Supine & 3 & $\begin{array}{l}\text { Whip-Mix } \\
\text { articulator, } \\
\text { instrument based on } \\
\text { the Buhnergraph, } \\
\text { and microscope }\end{array}$ & NR \\
\hline $\begin{array}{l}\text { Hobo and } \\
\text { Iwata }^{10}\end{array}$ & NR & NR & NR & 3 & $\begin{array}{l}\text { Experimental } \\
\text { electronic } \\
\text { mandibular } \\
\text { recording } \\
\text { microcomputer }\end{array}$ & 1 \\
\hline $\begin{array}{l}\text { Keshvad and } \\
\text { Winstanley }^{11}\end{array}$ & NR & $\begin{array}{l}\text { at approximately } \\
\text { the same time } \\
\text { of day }\end{array}$ & Upright & $\begin{array}{l}4 \text { (initially, after } \\
1 \text { hour, after } 1 \text { day, } \\
\text { and after } 1 \text { week) }\end{array}$ & $\begin{array}{l}\text { Articulator (Denar } \\
\text { D4A), custom-made } \\
\text { mandibular position } \\
\text { indicator, and } \\
\text { stereomicroscope } \\
\text { modified (Olympus } \\
\text { OM-2) }\end{array}$ & 1 \\
\hline $\begin{array}{l}\text { Galeković } \\
\text { et } \mathrm{al}^{12}\end{array}$ & NR & $\begin{array}{l}\text { at approximately } \\
\text { the same time } \\
\text { of day }\end{array}$ & NR & $\begin{array}{l}4 \text { (initially, the next } \\
\text { day, after } 1 \text { week, } \\
\text { and after } 1 \text { month) }\end{array}$ & $\begin{array}{l}\text { Mandibular position } \\
\text { indicator (SAM } \\
\text { Prazisionstechnik } \\
\text { GmbH) }\end{array}$ & NR \\
\hline
\end{tabular}

Abbreviation: NR, not reported. 
after performing a CR technique when patient is in the supine position than when he or she is in vertical position, due to the force of gravity). ${ }^{17,19-21}$ In addition, for a guided method technique, different operators may apply different "levels of force" to an individual's chin, and this can influence the reproducibility results of the mandibular position in $\mathrm{CR}$ (i.e., greater chance of mandibular position variability). Therefore, in a study comparing CR techniques, it is essential that only one operator performs all CR techniques, and that all research participants are seated (upright position) or supine during the execution of $\mathrm{CR}$ techniques.

Only two articles reported that $C R$ techniques were performed at approximately the same time of day. ${ }^{11,12}$ However, these articles do not report whether the records were made in the morning, afternoon, or evening. According to studies in the literature, ${ }^{22,23}$ the period of the day (morning, afternoon, or evening) may have an influence on condylar positions after performing a CR technique. ${ }^{22,23}$ Therefore, in a clinical study, CR recordings should be performed in a single period of the day, that is, in the morning, afternoon or evening, and at approximately the same times within one of these periods. ${ }^{2}$ In addition, this information is important to facilitate the comparison of findings between studies. ${ }^{2}$

Only Keshvad and Winstanley and Galeković et al reported the time intervals in which $\mathrm{CR}$ recordings were performed (-Table 4). ${ }^{11,12}$ This information is very relevant as it indicates that at each time point all CR techniques were performed once. Furthermore, as all $\mathrm{CR}$ techniques were performed at each time point, they all received the same influence from the patient's emotional and muscle factors at each time point. Thus, this promotes methodological standardization, helping to avoid bias.

To achieve the CR, a deprogramming of proprioceptive memory and some degree of muscle relaxation are needed. Thus, to achieve these goals, it is possible to use the Lucia jig technique for a few minutes in the patient's mouth before performing a CR technique. ${ }^{24-27}$ This device avoids occlusal contacts of the posterior teeth, causing a deprogramming of the proprioceptive memory of the periodontal ligament and promoting the relaxation of the masticatory muscles. ${ }^{26}$ These factors facilitate the manipulation of the individual's jaw, helping to avoid its deviation to an incorrect position during the execution of a CR technique. ${ }^{26}$ Consequently, this contributes to obtaining a correct $\mathrm{CR}$ record. ${ }^{26}$ The six articles included in this systematic review reported the use of a jig (-Table 3 ). However, the time of use of this type of device by the participants of each study was only reported by Teo and Wise (10 minutes), Hobo and Iwata (20 minutes), Keshvad and Winstanley (15 minutes), and Galeković et al (5 minutes). ${ }^{9-12}$ The present systematic review recommends that future articles report how many minutes the participants used their jigs, as this allows for a more accurate comparison between articles.

Limitations of this review include the lack of information in the articles included regarding the number of operators, patient position, etc ( - Table 4); the lack of standardization of the devices used to compare the $\mathrm{CR}$ techniques, which prevented a statistical comparison between the articles; the lack of studies comparing graphical or physiological techniques; and the lack of studies evaluating completely edentulous individuals. Therefore, further clinical studies are recommended comparing the $\mathrm{CR}$ techniques evaluated in this systematic review, based on the reproducibility of the condylar positions in CR.

The findings and limitations of the present systematic review can help to establish the parameters for future clinical studies comparing CR techniques.

\section{Conclusion}

In this systematic review, the bimanual technique was often superior (generated greater reproducibility of the $\mathrm{CR}$ ) or at least equivalent to the chin point guidance technique. Therefore, for individuals with complete dentition and without temporomandibular disorders, the bimanual technique is more recommended.

\section{Conflict of Interest \\ None declared.}

\section{References}

1 The glossary of prosthodontic terms: ninth edition. J Prosthet Dent 2017;117(5S):e1-e105

2 de Moraes Melo Neto CL, da Silva EVF, de Sousa Ervolino IC, Dos Santos DM, de Magalhães Bertoz AP, Goiato MC. Comparison of different methods for obtaining centric relation: a systematic review. Gen Dent 2021;69(01):31-36

3 Palaskar JN, Murali R, Bansal S. Centric relation definition: a historical and contemporary prosthodontic perspective. J Indian Prosthodont Soc 2013;13(03):149-154

4 Wilson PHR, Banerjee A. Recording the retruded contact position: a review of clinical techniques. Br Dent J 2004;196(07): 395-402

5 Moher D, Liberati A, Tetzlaff J, Altman DGPRISMA Group. Preferred reporting items for systematic reviews and meta-analyses: the PRISMA statement. Int J Surg 2010;8(05):336-341

6 Jadad AR, Moore RA, Carroll D, et al. Assessing the quality of reports of randomized clinical trials: is blinding necessary? Control Clin Trials 1996;17(01):1-12

7 Kantor ME, Silverman SI, Garfinkel L. Centric-relation recording techniques-a comparative investigation. J Prosthet Dent 1972;28 (06):593-600

8 Simon RL, Nicholls JI. Variability of passively recorded centric relation. J Prosthet Dent 1980;44(01):21-26

9 Teo CS, Wise MD. Comparison of retruded axis articular mountings with and without applied muscular force. J Oral Rehabil 1981;8(04):363-376

10 Hobo S, Iwata T. Reproducibility of mandibular centricity in three dimensions. J Prosthet Dent 1985;53(05):649-654

11 Keshvad A, Winstanley RB. Comparison of the replicability of routinely used centric relation registration techniques. J Prosthodont 2003;12(02):90-101

12 Galeković NH, Fugošić V, Braut V, Ćelić R Reproducibility of centric relation techniques by means of condyle position analysis. Acta Stomatol Croat 2017;51(01):13-21

13 Kantor ME, Silverman SI, Garfinkel L. Centric relation recording techniques: a comparative investigation. J Prosthet Dent 1973;30 (4 Pt 2):604-606

14 Carwell ML, McFall WT Jr. Centric relation determinations: clinical and radiographic comparisons. J Periodontol 1981;52(07):347-353 
15 McWilliam JS, Isberg-Holm A, Hellsing G. A radiographic analysis of small changes in condylar position. Dentomaxillofac Radiol 1982;11(02):99-106

16 Hellsing G, Isberg-Holm A, McWilliam J. A comparative study of two techniques for recording centric relation. Dentomaxillofac Radiol 1983;12(01):5-12

17 Watanabe Y. Use of personal computers for Gothic arch tracing: analysis and evaluation of horizontal mandibular positions with edentulous prosthesis. J Prosthet Dent 1999;82(05):562-572

18 McKee JR. Comparing condylar position repeatability for standardized versus nonstandardized methods of achieving centric relation. J Prosthet Dent 1997;77(03):280-284

19 Federick DR, Pameijer CH, Stallard RE. A correlation between force and distalization of the mandible in obtaining centric relation. J Periodontol 1974;45(02):70-77

20 Campos AA, Nathanson D, Rose L. Reproducibility and condylar position of a physiologic maxillomandibular centric relation in upright and supine body position. J Prosthet Dent 1996;76(03): 282-287

21 Abbad NB, Srivastava R, Choukse V, Sharma V. Validity and reliability of intraoral conventional tracer and intraoral digital tracer in different positions for recording horizontal jaw relation in edentulous patients. J Indian Prosthodont Soc 2019;19(02): 159-165

22 Latta GH Jr. Influence of circadian periodicity on reproducibility of centric relation records for edentulous patients. J Prosthet Dent 1992;68(05):780-783

23 Shafagh I, Yoder JL, Thayer KE. Diurnal variance of centric relation position. J Prosthet Dent 1975;34(05):574-582

24 Linsen SS, Stark H, Klitzschmüller M. Reproducibility of condyle position and influence of splint therapy on different registration techniques in asymptomatic volunteers. Cranio 2013;31(01): 32-39

25 Dupas PH, Picart B, Lefevre C, Graux E. Centric relation and programming semiadjustable articulators with the universal jig. Part I: Technique. J Prosthet Dent 1990;64(02): 134-138

26 Nassar MSP, Palinkas M, Regalo SCH, et al. The effect of a Lucia jig for 30 minutes on neuromuscular re-programming, in normal subjects. Braz Oral Res 2012;26(06):530-535

27 Karl PJ, Foley TF. The use of a deprogramming appliance to obtain centric relation records. Angle Orthod 1999;69(02):117-124, discussion 124-125 